\title{
A Study of Various Aspects of Internet Financial Reporting: A Case of Malaysian Auditors
}

\author{
*Mohd Noor Azli bin Ali Khan, Nurul Ain binti Omar \\ Universiti Teknologi Malaysia, Malaysia \\ *m-nazli@utm.my
}

\begin{abstract}
The objective of this research is to analyse the important items in the disclosure of benefit IFR to company and users, factors companies to engage or not engage IFR and some audit issues that can be used to describe the level of IFR from auditor's perception. Questionnaires were distributed to 100 auditors. A total of 40 questionnaires were completed and returned, giving a response rate of 40 percent. Based on the literature review of the IFR from the survey towards auditors indicate three items of benefit IFR to user are helps users in the decision-making process, provides accessibility to the users, increase timeliness and efficiency in obtaining financial information. Meanwhile, three items on benefit IFR towards company are attract foreign investors, attract local investors, and promote company wider to the public. On the other hand, three factor influence companies to engage IFR because enhancement of corporate image, stability and improvement in share prices and competitors in the industry. Whilst, three-factor Company not to engage IFR because requires expertise from the company, concerned over disclosure of propriety information and concerned over security information. Finally, the findings of this study also cover audit issues, for example the conversion or transposition processes involved in publishing information on the internet is susceptible to error, information on the internet is exposed to access and modification by unauthorised users both external and internal to the reporting entity and that information on the internet has the potential to be very fluid. Lastly, the limitation of this study was also highlighted and there are suggestions for future research.
\end{abstract}

Keywords: Internet Financial Reporting, auditors, benefit, factor, audit issue and Malaysia

\section{Introduction}

Internet is a medium to communicate in order to exchange information globally and it brings opportunities in fast delivery and is economical in obtaining information (Al-Htaybat, 2011). When a company is willing to exchange business information on the internet, it becomes part of the company network by adopting IFR (Hansen, 2001). Any corporation in the world that has the intention of building business relationship globally must have corporate website to retain investor relations component of information (Lymer and Debreceny, 2003). In addition, the internet is a medium to deliver financial reports to users who need the information for a specific purpose (Fisher et al., 2004). Meanwhile, corporate information such as annual reports, financial press reports, newspapers and magazines are also important sources of information in a number of studies in order to assist users in making informative decision about a company, including investors (Alattar and AlKhater, 2007; Naseret al., 2003; Abdul Rahman, 2001). Adopting the internet has become a phenomenon throughout the world today and is continuously growing during the recent years (Moradiet al., 2011; Fisher et al., 2004). Companies use websites to deliver information to stakeholders of financial reporting (Fisher et al., 2004; Velmurugan, 2009). Many countries have also developed securities markets, such as Bursa Malaysia, which uses IT for corporate reporting and is very well established (Lymer and Debreceny, 2003). Moreover, the usage of the internet, known as IT, by firms has become increasingly sophisticated and more complex (Virginia and Michael, 2003). However, less researchers study the importance of IFR practices and the effectiveness in disclosing financial reporting (Mirshekary and Saudagaran, 2005; Ismail and Sobhy, 2009). The implementation of disclosing financial reporting using internet as a medium to deliver information creates unique opportunities, challenges and implication for auditors (Fisher et al., 2004). The technology gives the impact of implementing IFR and is derived from other factors such as globalisation and notion accountability, which brings changes in audit practice on financial reporting (Fisher et al., 2004; Sumianiet al., 2007). Yet, no specific body has issued a formal standard to highlight or investigate the issues of auditing in IFR practices (Fisher et al., 2004; Lymer and Debrecency, 2003; Ohman and Wallerstedt, 2012). The increasing number of financial reporting disclosures brings audit issues (Lymer and Debrecency, 2003) 
and subsequently, the disclosure of financial statement with some restrictions on information will increase the potential of misleading interpretation among users of financial reporting such as auditors (Lymer and Debrecency, 2003).

\section{Literature Review}

Background of Study: The implementation of disclosing financial reports using the internet as a medium to deliver information creates unique opportunities, challenges and implications for auditors (Stoelet al., 2012; Khadaroo, 2005; Fisher et al., 2004). The technology gives an impact on implementing IFR and there are also other factors such as globalisation and notion accountability which bring changes in practices of financial reporting and audit issues (Sumianiet al., 2007; Khadaroo, 2005; Fisher et al., 2004). Yet, no specific body has issued a formal standard to highlight or investigate the issues of auditing in IFR practices (Ohman and Wallerstedt, 2012; Fisher et al., 2004; Lymer and Debrecency, 2003). The increasing number of financial reporting disclosures brings audit issues as stated from previous studies (Stoelet al., 2012; Khadaroo, 2005; Lymer and Debrecency, 2003) and subsequently, the disclosure of financial reporting with some restrictions on information will increase the potential of misleading interpretation of information among users of financial reporting such as auditors of annual reports (Lymer and Debrecency, 2003). There are many researchers who have studied issues of financial reporting in many developing countries, bringing benefits toward users of corporate financial reporting (Ismail and Sobhy, 2009; Mirshekary and Saudagaran, 2005). Nevertheless, there is little empirical evidence on the factors, practices, and contributions to the disclosure of financial reporting in Asian-listed companies, especially in Malaysia (Ali Khan, 2010; Ho and Kar, 2001). For this reason, this study intended to investigate the important items in financial reporting disclosure and the criteria on the accessibility of financial reporting, along with some audit issues occurring alongside the auditing practice. On another aspect, there are less participation from respondents in the previous researches about the impact of IFR on audit professionals and auditing tasks and procedures, bringing to audit issues (Stoelet al., 2012; Ismail and Sobhy, 2009; Xiao et al., 2002). By implementing IFR, some audit problems have occurred and auditors' negative feedbacks need to be analysed on a more comprehensive framework (Ismail and Sobhy, 2009). Thus, this study intended to research IFR from the auditors' perspective whereby they are part of the users. As auditors, they are exposed to the IT system and must familiarise with the terms in the records, processes and report transactions or other related financial reporting to facilitate their understanding regarding disclosure issues (Ohman and Wallerstedt, 2012; Stoelet al., 2012; Khadaroo, 2005; Virginia and Michael, 2003; Ho and Kar, 2001).

Auditors serve a part towards contributing to the company's performance in measuring whether the company is up to standard. Hence, auditors nowadays face many IT environments which involve data received by electronic media rather than paper-based (Virginia and Michael, 2003). Thus, auditors should increase their awareness on the consequences of IFR in auditing (Khadaroo, 2005; Ismail and Sobhy, 2009). Moreover, paper-based environments such as traditional hard copy of financial reporting are static in nature (Khadaroo, 2005; Fisher et al., 2004). Also, in developing electronic reports using IFR, it needs reviews from securities regulators and audit standards so it is important to give guidelines and issue standards to the auditors on the implications of IFR from then manipulation in the data received (Lymer and Debreceny, 2003). As a result, the researcher noticed that there are an increasing number of unsatisfied users, especially auditors, toward organisations' behaviour for not really updating their financial statement of the current year, thus making it difficult for auditing purpose (Stoelet al., 2012; Joshi and Al-Modhahki, 2003). Thus, this study tried to minimise the loopholes that might exist in disclosures of IFR because users such as auditors want detailed information regarding the financial reporting disclosure (Khadaroo, 2005; Hay and Antonio, 1990). Hence, this research came up with content and presentation dimensions in order to know the important items in IFR and criteria on accessing financial reporting by internet according to the auditors. Furthermore, it aimed to find out the advantages and disadvantage of IFR disclosure followed by other issues in IFR such as the factors and benefits, and then some audit issues that ought to be highlighted. As for the limitation of knowledge regarding IFR issues, the researcher found that there are only a limited number from previous studies that had emerged to explain the needs of financial reporting in company websites and to study audit issues in detail, especially in Malaysian context (Khadaroo, 2005). 
This study particularly intended to increase awareness and provide some insights to researchers, financial reporting regulators of companies who have implemented IFR, and users of financial reporting in Malaysia. Thus, useful financial reporting should be presented in an understandable, credible and timeliness manner as they are important characteristics influenced by both preparers and users of financial reporting (Naseret al., 2003). It is also hoped that this research becomes a basis for other studies to explore more on IFR disclosure's important items which highlight the auditor as the main indicator to research in detail and therefore come up with more issues in the auditing profession and solutions on this practice to enhance the credibility of IFR for auditors. It seems that adopting the internet has become a phenomenon in the world today and is continuously growing during recent years (Moradiet al., 2011; Fisher et al., 2004). Companies use their website to deliver information on the financial reporting to stakeholders (Velmurugan, 2009; Fisher et al., 2004). Many countries have also developed securities markets, such as Bursa Malaysia which uses IT for corporate reporting and is very well-established (Lymer and Debreceny, 2003). Moreover, the usage of the internet, known as IT, by firms has become increasingly sophisticated and more complex (Virginia and Michael, 2003).

Previous Studies: Implementing IFR could be beneficial to companies because they are able to develop strong business relationships among stakeholders, easily attract investors, enhance corporate image globally, and also discharge accountability (Velmurugan, 2009; Sumianiet al., 2007; Kaye, 1995). On the other hand, concern on security issues lead to the company not to engage in IFR because their disclosed information are exposed to higher risk of attracting hackers, crackers, and disgruntled insiders (Velmurugan, 2009; Hansen, 2001). Moreover, the cost of implementing the practice is quite high which requires expertise so this is a constraint in IFR (Sumianiet al., 2007). On the other hand, compared to the traditional methods, IFR is the medium to provide accessibility in obtaining financial reports to users (Al-Htaybat, 2011). As mentioned before, IFR will retain business relations and is another way to enhance the corporate image globally (Lymer and Debreceny, 2003). IFR also promotes transparency of financial reporting information regarding the corporate activities (Ho and Kar, 2001; Rahman, 1998). Nowadays, changes in the development of IFR require auditors to move from paper-based to electronic-based reporting (Virginia and Michael, 2003). Reports incorporated in printed financial reporting make it easier for the auditors to recognise the document (Debreceny and Gray, 1999). As mentioned, the criteria of financial reporting consist of timeliness and reliability which are important especially in the auditing environment. Thus, reliability is an important element for auditing purposes to make sure the information received are good quality, free from errors of fraud, and represent the accurate information (Ku Ismail and Chandler, 2005). In other words, reliability is important to be highlighted and is not specifically subjected to the auditor himself but also concerns the information in financial reporting that is disclosed frequently are exposed to a high risk of accounting errors. Hence, several factors impacted to lower reliability of the information being audited such the factors are the lack of planning and conducting the financial reporting properly for internal auditors in disclosing information on the internet, independence, technical competence, team experience, and quality control issues (Stoelet al., 2012). Nowadays, the evaluation on the development of the IFR practiced brings a lot of issues that should be highlighted in the auditing environment such as the quality of information of the financial reporting disclosure and security issues. These will be elaborated in the subsection, followed by some recommendations for improvements.

With the advancement of the IT, most companies have started to implement IFR and therefore the law on document issues for compliance to information discloses needs to be set (Stoelet al., 2012). In addition, there are main issues in the auditors' environment such as the role and responsibility of information on websites, the high potential of unaudited financial reporting, omission of audit reports, inappropriate audit issues, and also the timing and nature of the content form of audit reports on the website (Griffiths, 2012; Ismail and Sobhy, 2009; Fisher et al., 2004; Lymer and Debreceny, 2003; Xiao et al., 2002). Consequently, the lack of information in the financial reporting presented on the internet poses a problem to auditors (Debreceny and Gray, 1999). In addition, financial reporting on the internet has the high risk of not-updated data which reduces the reliability of the information (Ismail and Sobhy, 2009; Xiao et al., 2002). Thus, it is the responsibility of internal auditors to ensure the consistency between web-based audited financial reporting and other information regarding financial reporting published on the corporate website to avoid misinterpretation on the information disclosed (Fisher et al., 2004). Usually an annual report shows a part of the corporate website, so there is a potential number of misleading information alongside the financial data. 
Thus, if the data is not relevant to be audited due to the misleading information, it becomes problematic for the auditing purpose (Lymer and Debreceny, 2003). The lack of information and not-updated events are major factors faced by auditors and so they have to be responsible when evaluating information on financial reporting that are less clear when the statement is only part of a comprehensive one which focuses on investor-relations website (Debreceny and Gray, 1999). Sometimes, there are some errors when publishing information on the internet during the conversion or transposition process. Moreover, the information presented can be modified by unauthorised users such as those internal or external to the presenting financial reporting (Velmurugan 2009; Fisher et al., 2004; Hansen, 2001). Naturally, financial reporting is presented in a business reporting nature and so not all the information are disclosed in detail in the company's financial reporting. Thus, these situations make it difficult for the auditors of the data to get relevant information on the company (Lymer and Debreceny, 2003).

It is important for auditors to make sure the information are accurate, relevant, timely, and reliable, and can avoid security problems for the data that is being audited (Griffiths, 2012). In other words, the information must be compliant, accurate, and follows the regulation when being audited. Hence, from the problems in financial reporting information disclosure, there are needs for regulations to control the growing number of IFR usage to avoid security problems (Xiao et al., 2002). This is important to improve the regulatory framework regarding the corporate governance and financial reporting and disclosure (Ho and Kar, 2001). Thus, the lack of an issued standard is an unresolved problem because the implementation brings complexity to the practice (Griffiths, 2012). The nature of the evidence of document reviews on the internet brings additional risk associated with the online system and the litigation risks for auditors may also increase (Fisher et al., 2004). Other than that, audit reports are always exposed to security problems due to the change of information by others such as hackers which will increase the risk in IFR (Ismail and Sobhy, 2009). Other than that, organisations that lack in managing their website and the ability to have all web resources will bring problems to the auditors (Debreceny and Gray, 1999). This is proven where only 35 percent of the responding firms provided direct assurance to the users on the accuracy of the information which they provided via online on their website (Ashbaughet al., 1999). As there is limited knowledge for the researchers, there is no national professional body issuing formal standard to address any specific auditing issues that have been stated (Fisher et al., 2004). Currently, unregulated financial reporting disclosure on the internet arose because the global nature and the law stated that the internet environment is not appropriate for auditing purposes (Stoelet al., 2012; Fisher et al., 2004; Lymer and Debrecency, 2003).

The rate of financial reporting in Malaysia is low which shows the list of companies in Malaysia that disclose their financial reporting in general information to users (Sumianiet al., 2007). Legal regulations on the auditing rules are part of the Companies Act and were found lacking, or rather, it was difficult to formalise the auditing rules (Ohman and Wallerstedt, 2012). Moreover, there is no specified formatting structure or rules and requirements on how the auditing work should be performed in IFR (Ohman and Wallerstedt, 2012). In addition, the reliance on IT for the auditors brought to the need to set up new regulations regarding the auditing practice in IFR (Stoelet al., 2012). Therefore, a standard in auditing should be set up to minimise audit issues by producing new form of reporting using frequency and data orientation rather than information orientation (Ismail and Sobhy, 2009; Griffiths, 2012). Hence, by applying a set of regulations and law will bring improvement in the auditing practice (Ohman and Wallerstedt, 2012; Stoelet al., 2012; Velmurugan, 2009). However, accepting the law may affect the auditing development in the current practice because there will be standard regulations to be followed. From the audit issues highlighted, some improvements such as an increase in the quality of the IT audit process will improve the IFR results (Stoelet al., 2012). In other words, by identifying the critical challenges on the audit process, it could bring better control and management on the audit process properly to enhance the effectiveness and efficiency of the audit. Thus, it is important for auditors to understand IT-related aspects in the auditing process (Stoelet al., 2012). In the UK, the issues of auditing standards and auditor's knowledge on information system (IS) are run between the Public Company Accountant Oversight Board (PCAOB) and the Standing Advisory Group (SAG). It covers the issue of the importance of IT for auditing and IT expertise to access the control especially to external auditors (Stoelet al., 2012). In short, there is a need for a professional body in Malaysia to issue the specific standards and to highlight the issues of using the internet in auditing practices. 


\section{Methodology}

Data Collection: The main and only method adopted by the researcher to collect the primary data was through questionnaire distribution. A questionnaire is a tool comprising different types of questions to obtain useful information about the study area which is then analysed and validated statistically for the ease of effectively managing and administrating data and categorising them for analysis (Davies, 2007; Creswell, 2005). Users of financial reporting are classified as share brokers, business owners, graduates, academicians and public users who are exposed to the accounting field and have the essential knowledge to deal with financial reporting (Mohd Isa, 2006). For this research, auditors were chosen as a proxy group for financial reporting users because auditors should be familiar with the IT system that is used by firms to determine the terms in the records, processes, report transactions and other financial data in the financial reporting report (Stoelet al., 2012; Khadaroo, 2005; Virginia and Michael, 2003). The questionnaires were given personally to the auditors who were randomly selected from the list provided by MIA. The questionnaires were put into an envelope with the address of the company. The questionnaires handed out personally, they came with a return envelope addressed and given directly to the respondents. Each company received five set of questionnaires to be distributed among the staffs in the auditing field. They were given two weeks to fill up the entire questionnaires and extended time was granted based on respondent's need.

Sample and Data: Sample size is used to identify the population to be selected for the purpose of the research (Devies, 2007; Creswell, 2005). In other words, the sample size plays an important part to identify the accuracy of the data involved. Thus, the accuracy level of a research can be measured in a suitable, appropriate sample size (Bartlett et al., 2001). Hence, to decide the size of the population, the researcher used the sample size in a range of 36 from the population of 40 audit companies in south of Johor Bahru (Krejcie and Morgan, 1970). The total sample size shows the number of respondents in the population that answered the questionnaire. A valid sample size would involve missing or invalid respondents such as those who did not answer the questionnaire and are recorded as missing value (Heller and Greene, 2012). This study uses face-to-face survey where the questionnaires were distributed to auditors in several cities in the south of Johor Bahru, namely Skudai, PusatBandaraya, Larkin, Taman Pelangi, and Bandar BaruUda.

Respondent Rate: Only 40 completed questionnaires were collected which represents a response rate of 40 percent. The rate is similar to the percentage of previous studies with response rate of 43 percent (Mohd Isa, 2006), 49 percent (Mirshekary and Saudagaran, 2005), followed by other researchers' response rate in the range of ten percent or less (Frazer and Lawley, 2000), 10.3 percent (Lenget al., 2007), 13.29 percent (Mohd Isa, 2006), 17.2 percent (Ho and Wong, 2001), 14.4 percent (Ku Ismail and Chandler, 2005), 20 percent (Staden, 1998), and 27 percent (Ousamaet al., 2011). Hence, the response rate of this research is acceptable and reliable when compared to previous studies. In addition, many efforts had been taken to improve the response rate, including extending the period of collecting the questionnaires from the respondents and also minimising the length of the questionnaire. After the questionnaires were collected by the researcher, all the data were entered into the SPSS software to process the raw data. The analysis of the data collected used three steps to measure the accuracy and validity, namely Cronbach's Alpha Reliability Test, Descriptive Analysis, and Frequency Analysis. Thus, the analysis identified the result structure and the interpretation about the data collected (Marshall and Rossman, 1999). In other words, data analysis is an important step to measure the accuracy and validity of the data to obtain the result. Hence, the output will be discussed in chapter 4 which will cover the findings and analysis.

Cronbach's Alpha Reliability Test: Cronbach's Alpha Reliability Test is the first step in analysing data which measures the level of accuracy and reliability of the data acquired from the questionnaire (Creswell, 2005; Field, 2005). For the result, each dimension to obtain the auditors' perception on IFR that scores a reliability coefficient (alpha) of greater than 0.7 is accepted as reliable in this study (Radhakrishna, 2007; Field, 2005) whereas to measure the method of internal consistency of each dimension presented, reliability concept was used to measure it (Coakes and Ong, 2011).

Descriptive Analysis: To measure the accuracy of the research, descriptive statistics were used in order to compute the data collected. Descriptive figure is used to examine the validity of the sample data (Heller and Greene, 2012). By adopting descriptive analysis, the major types of descriptive statistics such as frequencies, 
mean, variance, standard deviation, measure of control tendency, range, and maximum and minimum scores can be identified. Mean is used to make some general information about the data collected by used frequency of each items presented while standard deviation and variance give more information about the distribution of each variable (Heller and Greene, 2012). Making classification on mean makes it easier to comprehend; for example, the classification of mean that has been used in a previous study were: greatly important for mean exceeding 4.00, moderately important for mean in the range of 3.00 to 4.00, and slightly important for mean less than 2.00 (Mirshekary and Saudagaran, 2005; Ali Khan, 2010). In this study, descriptive analysis was used to determine the important items disclosure of the content and presentation dimensions, advantages and disadvantages, others factors and audit issues.

Frequency Analysis: Frequency refers to the number of respondents who answered the particular questions and count usually refers to the number of time the questions were answered. Hence, with descriptive statistics, it measures the number of time each value occurs in a variable (Heller and Greene, 2012). In this study, frequency analysis was used only to identify the demographic profile of the 40 respondents. The data were analysed and then presented in frequency polygons such as table form.

\section{Results}

Demographic Background: Table 1 displays the demographic background details obtained from 40 respondents which are auditors from south Johor Bahru who are involved in this study. Hence, out of the 40 auditors, 10 were male ( 25 percent) and 30 were female respondents (75 percent). In terms of age, 26 auditors were aged below 30 years old (65 percent) and 14 auditors were between 31 to 40 years old (35 percent). Only five auditors were diploma holders ( 12.5 percent) while 32 respondents were degree holders (80 percent) and only three were master's holder ( 7.5 percent). For the scope of their academic field, most of them had an accounting background ( 85 percent) and only a small amount were from the accounting and finance field which is only six auditors (15 percent). In addition, most of the respondents have had experience in the auditing field for less than five years which are 27 people (67.5 percent) while in between five to ten years, there are 10 respondents (25.2 percent), and only one auditor had between 11 to 15 years (2.5 percent) while two auditors have worked around 16 to 20 years (5.0 percent).

Table 1: Profile of Auditors ( $\mathrm{n}=40)$

\begin{tabular}{llll}
\hline Demographic & Item & Frequency & Percentage (\%) \\
\hline Gender & Male & 10 & 25 \\
& Female & 30 & 75 \\
Age & $<30$ years & 26 & 65 \\
& $31-40$ years & 14 & 35 \\
Academic qualification & Diploma & 5 & 12.5 \\
& Degree / Professional & 32 & 80 \\
Majoring & Master & 3 & 7.5 \\
\multirow{2}{*}{ Number of years } & Accounting & 34 & 85.0 \\
organisation & Accounting \& Finance & 6 & 15.0 \\
& $<5$ years & 27 & 67.5 \\
& $5-10$ years & 10 & 25.2 \\
& $11-15$ years & 1 & 2.5 \\
\hline
\end{tabular}

Reliability: This section will discuss the level of reliability of each dimension presented such as the content and presentation dimensions of IFR and advantages and disadvantages of IFR, followed by other issues such as benefits of IFR among user and company, the factors that engage or do not engage companies in IFR, and lastly audit issues regarding IFR disclosure. As discussed in the methodology part, it was indicated that the level of reliability of each dimension can be measured by the internal consistency (Ousamaet al., 2011). Table 2 shows the values of Cronbach's Alpha of each dimension. From the result, each issues presented must score a reliability coefficient (alpha) of greater than 0.7 to be considered accepted as reliable in this study (Radhakrishna, 2007; Field, 2005). The table shows that Cronbach's alpha on benefits to company is 0.896, benefits to users is 0.903 , factors company engage in IFR is 0.873 , factors company do not engage in IFR is 
0.880 , and audit issues is 0.890 . Overall, the alpha value of each dimension is reliable and all constructs in this study will be presented in the next sub-section.

Table 2: The Level of Reliability $(n=40)$

\begin{tabular}{lll}
\hline Dimension & No. of Item & Cronbach's Alpha \\
\hline Benefits to company & 9 & 0.896 \\
Benefits to users & 6 & 0.903 \\
Factors company engage in IFR & 11 & 0.873 \\
Factors company do not engage in IFR & 11 & 0.880 \\
Audit issues & 7 & 0.890 \\
\hline
\end{tabular}

Other Factors of IFR: This section will identify the other factors of IFR consisting of benefits of IFR for companies and users and after that, the factors that engage and do not engage companies to implement IFR practice will be discussed.

Benefits to Company: Table 3 shows that: (1) attract foreign investors, (2) attract local investors, and (3) promote company wider to the public, are the three important items which exceed the mean score of 4.00; whilst the three least important items are: (1) enhance managerial efficiency, (2) improve financial performance, and (3) discharge accountability, in which these are classified as the moderately important for having mean score exceeding 3.50 but below 4.00. These have similarity with previous research by implementing IFR could be beneficial to companies because they would be able to develop strong business relationship with stakeholders and can also easily attract investors, enhance corporate image globally, and discharge accountability (Velmurugan, 2009; Sumianiet al., 2007; Kaye, 1995). IFR promotes transparency in financial reporting information regarding corporate activities as well (Ho and Kar, 2001; Rahman, 1998).

Table 3: Auditor Perception on the Benefits to Company

\begin{tabular}{|c|c|c|c|c|}
\hline \multicolumn{2}{|c|}{ Disclosure Item } & Mean & Std. Dev. & Rank \\
\hline \multicolumn{5}{|c|}{ Greatly Important } \\
\hline 1 & Attract foreign investors & 4.45 & .552 & 1 \\
\hline 2 & Attract local investors & 4.32 & .656 & 2 \\
\hline 3 & Promote company more wider to the public & 4.27 & .640 & 3 \\
\hline 4 & Provide wider coverage & 4.18 & .594 & 4 \\
\hline 5 & Promote transparency & 4.18 & .675 & 5 \\
\hline 6 & Attract potential customers & 4.12 & .853 & 6 \\
\hline \multicolumn{5}{|c|}{ Moderately Important } \\
\hline 7 & Enhance managerial efficiency & 3.95 & .749 & 7 \\
\hline 8 & Improve financial performance & 3.93 & .764 & 8 \\
\hline 9 & Discharge accountability & 3.92 & .829 & 9 \\
\hline
\end{tabular}

(1 = strongly disagree at all; 5 = strongly agree)

Benefits to Users: Next, in Table 4, respondents were asked to offer their perception regarding the benefits of IFR toward themselves. From the result, respondents ranked the five most important items as: (1) helps users in the decision-making process, (2) provides accessibility to the users, (3) increase timeliness and efficiency in obtaining financial information, (4) makes investment decision process easier and faster, (5) provides information for the company inexpensively, and (6) Provide another medium of disclosure. Moreover, all the items presented in Table 4.8 were classified as greatly important with the mean exceeding 4.00 , indicating that the auditors gave positive feedback on IFR being very useful among users. From the findings, indicate that result obtain are consistent compare to previous study. Using IFR could be beneficial to users to enhance wider reach especially to investor in order to makes investment decision process easier and faster, and is easy to access to the user just click the items needed to get the information provided (Debrecenyet al., 2002). On the other hand, IFR provides another medium of financial reporting disclosure 
from the existing printed financial report by using HTML or Acrobat (Lymer and Debreceny, 2003). Compared to the traditional method which is existing printed financial report, IFR is another medium to provide users accessibility and make decision to obtain the financial reports (Al-Htaybat, 2011).

Table 4: Auditor Perceptions on the Benefits to Users

\begin{tabular}{|c|c|c|c|c|}
\hline \multicolumn{2}{|c|}{ Disclosure Item } & Mean & Std. Dev. & Rank \\
\hline \multicolumn{5}{|c|}{ Greatly Important } \\
\hline 1 & Helps users in the decision-making process & 4.25 & .707 & 1 \\
\hline 2 & Provides accessibility to the users & 4.17 & .549 & 2 \\
\hline 3 & Increase timeliness and efficiency in obtaining financial information & 4.15 & .533 & 3 \\
\hline 4 & Makes investment decision process easier and faster & 4.08 & .656 & 4 \\
\hline 5 & Provides information for company, inexpensively & 4.08 & .656 & 5 \\
\hline 6 & Provides another medium of disclosure & 4.07 & .616 & 6 \\
\hline
\end{tabular}

(1 = strongly disagree at all; 5 = strongly agree)

Factors Companies Engage in IFR: Among the top five factors influencing companies to engage in IFR in Table 5 are: (1) enhancement of corporate image, (2) stability and improvement in share prices, (3) competitors in the industry, (4) obtain funds from wider sources, and (5) obligations to the community. Meanwhile, the three least important factors influencing companies to engage in IFR are: (1) receive government support, (2) pressure from stakeholders, and (3) win awards. The finding shows that all items presented exceeded the mean of 3.50 and only one exceeded 4.00 which is (1) enhancement of corporate image. Factor influence companies to engage to IFR are consistent with previous research because will retain business relations for company as a part of component to obtain information and is another way to enhance the corporate image globally (Lymer and Debreceny, 2003). Meanwhile, factor influence company not to engage IFR due to cost of implementing the practice is quite high and requires the expertise and so this becomes a constraint to IFR (Sumianiet al., 2007). By using IFR to disclose financial reporting has not really obtained positive feedback and very few implement it as most firms prefer to use manual ways such as hardcopy to represent their financial report due to lack of knowledge on the internet (Celiket al., 2006).

Table 5: Auditor perceptions on the factor influence company to engage to IFR

\begin{tabular}{|c|c|c|c|c|}
\hline \multicolumn{2}{|c|}{ Disclosure Item } & Mean & Std. Dev. & Rank \\
\hline \multicolumn{5}{|c|}{ Greatly Important } \\
\hline 1 & Enhancement of corporate image & 4.27 & .716 & 1 \\
\hline \multicolumn{5}{|c|}{ Moderately Important } \\
\hline 2 & Stability and improvement in share prices & 3.93 & .694 & 2 \\
\hline 3 & Competitors in the industry & 3.85 & .580 & 3 \\
\hline 4 & Obtain funds from wider sources & 3.82 & .594 & 4 \\
\hline 5 & Obligations to the community & 3.82 & .712 & 5 \\
\hline 6 & Media attention & 3.80 & .723 & 6 \\
\hline 7 & Company teller with the technology development & 3.78 & .660 & 7 \\
\hline 8 & Directors desire to engage IFR & 3.65 & .700 & 8 \\
\hline 9 & Receive government support & 3.65 & .834 & 9 \\
\hline 10 & Pressures from stakeholders & 3.62 & .628 & 10 \\
\hline & Win awards & 3.55 & .815 & 11 \\
\hline
\end{tabular}

$(1$ = strongly disagree at all; 5 = strongly agree $)$

Factors Companies Do Not Engage in IFR: On the other hand, the five important items that were the factors companies do not engage in IFR in Table 6 are (1) requires expertise from the company, (2) concerned over disclosure of propriety information, (3) concerned over security information, (4) no legal requirement, and (5) fear of losing competitive advantage. Whilst the three least important items of factors that influence companies to not engage in IFR are: (1) cost incurred outweighs benefits to company (2) there are alternative forms of obtaining information, and (3) potential legal liability. From the result, most of the items presented exceeded the mean score of 3.50 with three of them categorised as greatly important as they exceeded the 
mean score of 4.00. These result consistent with previous research due to concerns over security issues lead to companies not to engage in IFR because the information disclosed would be exposed to higher risk of attracting hackers, crackers and disgruntled insiders (Velmurugan, 2009; Hansen, 2001). IFR is exposed to the risk of unauthorised access when it is not properly managed by experience person which then leads to other people inserting errors into the data files, causing security problem (Stoelet al., 2012; Hansen, 2001).

Table 6: Auditor Perceptions on the Factor Influence Company not to Engage to IFR

\begin{tabular}{|c|c|c|c|c|}
\hline \multicolumn{2}{|c|}{ Disclosure Item } & Mean & Std. Dev. & Rank \\
\hline \multicolumn{5}{|c|}{ Greatly Important } \\
\hline 1 & Requires expertise from the company & 4.08 & .616 & 1 \\
\hline 2 & Concerned over disclosure of proprietary information & 4.05 & 639 & 2 \\
\hline 3 & Concerned over security of information & 4.02 & .768 & 3 \\
\hline \multicolumn{5}{|c|}{ Moderately Important } \\
\hline 4 & No legal requirement & 3.88 & .911 & 4 \\
\hline 5 & Fear of losing competitive advantage & 3.85 & .622 & 5 \\
\hline 6 & Need to keep information updated to be of use & 3.82 & .636 & 6 \\
\hline 7 & Too costly to setup and maintain & 3.80 & .758 & 7 \\
\hline 8 & Do not want to be too transparent & 3.80 & .791 & 8 \\
\hline 9 & Cost incurred outweighs benefits to company & 3.72 & 679 & 9 \\
\hline 10 & There are alternative forms of obtaining information & 3.70 & .791 & 10 \\
\hline & Potential legal liability & 3.70 & .791 & 11 \\
\hline
\end{tabular}

(1 = strongly disagree at all; 5 = strongly agree)

Audit Issues: The previous studies stated that the widespread usage of disseminating financial reporting and the lack of standardisation on audit might affect the auditor's perception on IFR which brings a lot of audit issues (Ismail and Sobhy, 2009). However, until now no regulation, rules or standard has been issued on the IFR to cover the audit problems (Ismail and Sobhy, 2009). In Table 7, analysis was carried out to investigate the perception of auditors toward audit issues by implementing IFR. These items were extracted from previous studies as mentioned in the methodology part (Griffiths, 2012; Ismail and Sobhy, 2009; Fisher et al., 2004; Lymer and Debreceny, 2003; Xiao et al., 2002). The perceptions were elicited using a Likert scale ranging from 1 strongly disagreed to 5 strongly agree. The result in Table 8 shows that three items exceeded the mean value of 4.00, which are: (1) conversion or transposition process involved in publishing information on the internet is susceptible to error, (2) information on the internet is exposed to accessibility and modification by unauthorised users both external and internal to the reporting entity, and (3) information on the internet has the potential to be very fluid. Meanwhile, three lowest items in audit issues are; (1) unaudited information is incorporated with audited information (2) Timeliness in corporate disclosure and greater depth and breadth of disclosure, and (3) Information from external sources can be easily incorporated into corporate website through hyperlinks. All the items presented in Table 7shows, by implementing IFR will expose disclosed information to be easily manipulated and will incur error and security problem (Ali Khan and Ismail, 2012; Ali Khan and Ismail, 2009; Joshi and Al-Modhahki, 2003). As a conclusion, all the items present in the auditor issues dimension are relevant because they exceeded the mean value of 3.50 .

Result from audit issues in Table 7 are consistent with previous studies indicated that the increasing number of auditors dissatisfaction regarding financial reporting are that it is not updated in the current year which delays financial reporting publishing and it lacks access to adequate information (Mirshekary and Saudagaran, 2005; Joshi and Modhahki, 2003; Naseret al., 2003; Ho and Kar, 2001). In addition there are high potential of unaudited financial reporting, omission of audit reports, and also the timing and nature of the content form of audit reports on the website (Griffiths, 2012; Ismail and Sobhy, 2009; Fisher et al., 2004; Lymer and Debreceny, 2003; Xiao et al., 2002). Important criteria of financial reporting consist of timeliness and reliability which are important especially in the auditing environment. Thus, reliability is an important element for auditing purposes to make sure the information received are good quality, free from errors of fraud, and represent the accurate information (Ku Ismail and Chandler, 2005). Hence, several factors 
impacted to lower reliability of the information being audited; the factors are the lack of planning and conducting the financial reporting properly for internal auditors in disclosing information on the internet, independence, technical competence, team experience, and quality control issues (Stoelet al., 2012).

\section{Table 7: Auditor Issues of IFR}

\begin{tabular}{|c|c|c|c|c|}
\hline \multicolumn{2}{|c|}{ Disclosure Item } & Mean & Std. Dev. & Rank \\
\hline \multicolumn{5}{|c|}{ Greatly Important } \\
\hline 1 & $\begin{array}{l}\text { Conversion/transposition process involved in publishing information } \\
\text { on the Internet is susceptible to error }\end{array}$ & 4.02 & .733 & 1 \\
\hline 2 & $\begin{array}{l}\text { Information on the Internet is exposed to access and modification by } \\
\text { unauthorised users both external and internal to the reporting entity }\end{array}$ & 4.02 & .832 & 2 \\
\hline 3 & Information on Internet has the potential to be very fluid & 4.00 & .751 & 3 \\
\hline \multicolumn{5}{|c|}{ Moderately Important } \\
\hline 4 & Misleading information alongside the financial data & 3.98 & .620 & 4 \\
\hline 5 & Unaudited information is incorporated with audited information & 3.98 & .660 & 5 \\
\hline 6 & $\begin{array}{l}\text { Timeliness in corporate disclosure and greater depth and breadth of } \\
\text { disclosure }\end{array}$ & 3.92 & .616 & 6 \\
\hline 7 & $\begin{array}{l}\text { Information from external sources can be easily incorporated into } \\
\text { corporate website through hyperlinks }\end{array}$ & 3.90 & .709 & 7 \\
\hline
\end{tabular}

In addition, the objective of this study brought up other issues on IFR such as the benefit of IFR towards companies and users. It also covered the issue of factors that do and do not engage companies in IFR. Thus, it is an important exposure for companies to look seriously on their impact to the growth of IFR and therefore implement the practice in their companies and for responsible bodies to take action in minimising the problems that occur during the implementation of IFR. The last objective is to analyse auditors' issues in IFR and this is another main fundamental objective to be achieved in this study because its respondents are the auditors in south of Johor Bahru. This research acquired their perception and feedback regarding the implementation of IFR from the questionnaires distributed because they are exposed to the IT system and so are familiar with the terms in the records, processes and report transactions or other related financial data to facilitate their understanding regarding disclosure issues (Virginia and Michael, 2003; Ho and Kar, 2001). Hence, auditor is the profession that uses financial reporting the most to evaluate the company's performance. Thus, this research wants to analyse the issues of IFR in the aspect of the auditor's responsibility. Perhaps, a specific standard for professional auditing can be constructed with rules and regulations to minimise the issues of auditors. It would help that quality IT audits can be implemented in Malaysia as has been discussed in the Literature Review part.

\section{Conclusion}

Factor contribute company to engage IFR because as a medium to improve their company image, also to improve their stability in share price and to enhance the competitors in the industry. Meanwhile, several factors leads company do not engage IFR because it requires expertise from the company, also company concerned their disclosure of proprietary information and lack of the security of information. On the other hand, auditors indicate the important IFR to company because as attraction for foreign also local investor and would promote company wider to the public. Whilst, the benefit IFR toward user contribute to help them in the decision making process, also provides accessibility and increase timeliness and efficiency in obtaining financial information. For the third objective, the auditors' perception and feedback indicated that the three items important in audit issues are that the auditors perceived conversion or transposition process involved in publishing information on the internet as susceptible to error, information on the internet is exposed to accessibility and modification by unauthorised users both external and internal to the reporting entity, and that the information on the internet has the potential to be very fluid. As for the result, all the items presented exceeded the mean value of 3.50. It may be that the problems could be minimised if professional 
bodies such as the International Financial Reporting Standards (IFRSs) and International Standards on Auditing (ISAS) were used as benchmark for the national standard (Ismail and Sobhy, 2009).

This study was conducted in order to evaluate the important items of IFR in terms of the content and presentation dimensions presented in financial reporting of IFR, the advantages and disadvantages of IFR, others issues, and some audit issues that had brought dissatisfaction to the auditors. The result of this study contributes to provide understanding to the preparers and users in obtaining information regarding IFR issues so that they can come up with solutions for and take action from the problems that were highlighted. It provides critical information especially for auditors on the issues in auditing and also some views on IFR practice as they are more alert to any consequence that occurs while implementing IFR. Based on the literature review, there are limited efforts from the previous studies regarding analysing the need for items checklist in financial reporting such as the content and presentation dimensions presented in this study. From the limited knowledge of researchers from some previous studies, they only highlighted the content on financial reporting but did not take into consideration the needs of users of financial reporting such as the presentation dimension studied in this research which has brought to the effectiveness when using IFR as an attraction to users to obtain information. Moreover, there are limited efforts from previous studies to explore in detail the contributions on auditors in which IFR can create unique opportunities, challenges and implications for the auditing profession (Fisher et al., 2004). In other words, they have not simplified the needs of the auditors and ways to minimise the problems that occur. Hopefully, other researches will investigate in detail the problems regarding auditors implementing IFR practice and come up with the solution to minimise the problems that occur.

Thus, the result of this study is important to the construction of individual checklist because it seeks to contribute to empirical evidences for Bursa Malaysia on the items needed in the content and presentation dimensions. Additionally, there is no action from the professional body issuing a formal standard for IFR (Fisher et al., 2004). In other words, no standardisation is assembled to improve the quality of IFR to make it more attractive and useful towards users in Malaysia. Hence, the result gained from the study can be a guideline for preparers of financial reporting to take action for continuous improvement and to minimise past mistakes from being repeated such as security problem and high degree of data manipulation. While the implementation IFR contributes to the benefits of users, there are still some limitations that should be looked into. In addition, this paper provided important insights to items disclosure in financial reporting, benefits, factors, advantages, disadvantages and audit issues of IFR from the perspective of auditors of financial reporting that were not specifically highlighted by previous studies. The limitations of this study were that it needed more time and more respondents to measure the validity of data. Perhaps, different results may have been achieved with higher potential on the accuracy of the data with increase the percentage number of respondents. The scope of this study was only focused in south Johor Bahru due to time constraint. Most of the respondents in this study were from the auditor group which are part of the users of financial reporting. However, the result of this study might not produce comprehensive result as they were only for auditor perceptions and not the variety of users of financial reporting such accountants, managers, academicians etc in order to know different perception in different type of users. Less participation from the respondents to answer the sets of questionnaire due to time constraints and also their less effort to fill up the questionnaires also affected the study which will be impact the validity of the final result.

As discussed in the previous chapter, implementation brought to the dissatisfaction of users of financial reporting where financial reports were not updated in the current year which put delay in publishing financial reporting and caused lack of access to adequate information (Stoelet al., 2012; Mirshekary and Saudagaran, 2005; Joshi and Modhahki, 2003; Naseret al., 2003; Ho and Kar, 2001). Furthermore, it may also have affected the perception of auditors toward IFR who are the main population of user of financial reporting. There are several suggestions provided by the researcher, mainly based on the limitation of the study as stated in the prior section. Hopefully, further research can be carried out involving a larger sample size. Besides that, the research can also be expanded to the other states in Malaysia to obtain more perception and feedbacks. Also, giving extension to the duration of collecting the questionnaires enables respondents to spend more time to answer the set of questionnaire. Other research procedures that can be used are emails or interviews to gain more feedback on IFR. Further researches can be carried by analyse what are the factors make disclosure of IFR not updated by take respondents from accountant and auditors to 
obtain their feedback. It important because accountant and auditors are the persons produces financial reporting and discloses the information to user of IFR. To make it more interesting, future researches can investigate the contribution of IFR in creating unique opportunities, challenges and implications for the auditing profession. Future research may also obtain feedback from the professional bodies regarding auditing issues in IFR and maybe they would consider issuing a standard regarding the auditors' practice on IFR. In addition, future research may obtain the feedback from securities bodies from Bursa Malaysia to enhance the security of information disclose.

Acknowledgement: The financial support for the authors' research from Ministry of Higher Education (MOHE), Malaysia and Research Management Centre (RMC), Universiti Teknologi Malaysia, Johor Bahru, Johor, Malaysia vote no. Q.130000.2629.07J40 by Research University Grant (RUG) also appreciated.

\section{Reference}

Abdul-Rahman, A. (2001). The Use and Perceived Importance of Annual Reports by Accountants in the Service Industry in Malaysia. Asian Review of Accounting, 9(2), 117-126.

Alattar, J. L. \& Al-Khater, K. (2007). An Empirical Investigation of Users' Views on Corporate Annual Report in Qatar. International Journal of Commerce and Management, 11(4), 312-325.

Al-Htaybat, K. (2011). Corporate Online Reporting in 2010: A Case Study in Jordan. Journal of Financing Reporting and Accounting, 9(1), 5-26.

Ali Khan, M. N. A. (2010). Pelaporan Kewangan Menerusi Internet Indeks, Tahap Pelaporandan Faktor Penentunya. Unpublished PhD Dissertation: Universiti Utara Malaysia, Sintok Kedah.

Ali Khan, M. N. A. \& Ismail, N. A. (2009).Internet Financial Reporting in Malaysia, Factors, Pros and Cons. Accountants Today, 22(2), 28-31.

Ali Khan, M. N. A. \& Ismail, N. A. (2011).The level of Internet Financial Reporting of Malaysian Companies. Asian Journal of Accounting and Governance, 2, 27-39.

Ali Khan, M. N. A. \& Ismail, N. A. (2012). Various Aspects of Internet Financial Reporting: Evidence from Malaysian Academician. Journal of Global Business and Economics, 4(1), 1-15.

Allam, A. \& Lymer, P. (2003). Development in Internet Financial Reporting: Review and Analysis across Five Developed Countries. The International Journal of Digital Accounting Research, 3(6), 165-199.

Ashbaugh, H., Johnstone, K. M. \& Warfirld, T. D. (1999). Corporate Reporting on the Internet. Accounting Horizons, 13(3), 241-257.

Barlett, J. E., Kotrlik, J. W. \& Higgins, C. C. (2001). Organizational Research: Determining Appropriate Sample Size in Survey Research. Information Technology, Learning, and Performance Journal, 9(1), 43-50.

Celik, O., Ecer, A. \& Karabacak, H. (2006).Impact of Firm Specific Characteristics on the Web Based Business Reporting: Evidence from the Companies Listed in Turkey. Problems and Perspectives in Management, 4(3), 100-133.

Coakes, S. J. \& Ong, C. (2011). SPSS version 18.0 for windows (version 18.0). Australia: John Wiley and Sons.

Creswell, J. W. (2005). Educational Research: Planning, Conducting, and Evaluating Quantitative and Qualitative Research. (2 ${ }^{\text {nd }}$ Ed.). New Jersey: Pearson Prentice Hall.

Creswell, J. W. (2009). Research Design: Quantitative, Quantitative, and Mixed Methods Approaches. (3 ${ }^{\text {rded.). }}$ United Kingdom: SAGE Publications.

Davies, M. B. (2007). Doing a Successful Research Project. (3 ${ }^{\text {rd }}$ Ed.). New York: Palgrave Macmillan.

Debreceny, R., Gray, G. L. \& Rahman, A. (2002).The Determinants of Internet Financial Reporting. Journal of Accounting and Public Policy, 21(4-5), 371-394.

Deller, D., Stubenrath, M. \& Weber, C. (1999).A Survey on the Use of the Internet for Investor Relations in the USA, the UK and Germany. The European Accounting Review, 8(2), 351-364.

Feher, A. \& Towell, E. (1997).Business use of the Internet. Internet Research, 7, 195-200.

Field, A. P. (2005). Discovering Statistics Using SPSS. (2 ${ }^{\text {nd }}$ Ed.). London: Sage.

Fisher, R., Oyelere, P. \& Laswad, F. (2004). Corporate Reporting on the Internet: Audit Issues and Content Analysis of Practices. Managerial Auditing Journal, 19(3), 412-439.

Frazer, L. \& Lawley, M. (2000).Questionnaire Design \& Administration. Australia: John Wiley \& Sons.

Griffiths, P. (2012). Information Audit: Towards Common Standards and Methodology. Business Information Review, 29(1), 39-51. 
Hansen, J. V. (2001). Internet Commerce Security: Issues and Model for Control Checking. Journal of the Operational Research Society, 52(10), 1159-1164.

Harry, N. B. \& Deborah, A. B. (2012).Analyzing Likert Data. Journal of Extension, 5(2), 1-5.

Hay, L. E. \& Antonio, J. F. (1990). What Users Want in Government Financial Reports. Journal of Accountancy. August, 91-98.

Heller, T. \& Greene, S. (2012). Using SPSS for Data Analysis: Support Document for SPSS Output Tables. UWStout Office of Planning, Assessment, Research and Quality (PARQ), 2-51.

Ho, S. S. M. \& Kar, S. W. (2001). A study of Corporate Disclosure Practice and Effectiveness in Hong Kong. Journal of International Financial Management and Accounting, 12(1), 75-100.

Ismail, T. H. \& Sobhy, N. M. (2009). Determinants of Auditors' Perception of the Work Needed in the Audit of Internet- Based Financial Report in Egypt. Journal of Applied Accounting Research, 10(2), 132-150.

Joshi, P. L. \& Al-Modhahki, J. (2003). Financial Reporting on the Internet: Empirical Evidence from Bahrain and Kuwait. Asia- Pacific Journal of Accounting, 11(1), 88-101.

Kaye, D. (1995). The Importance of Information. Library Management, 16(5), 6-15.

Khadaroo, I. (2005). Corporate Reporting on the Internet: Some Implication for the Auditing Profession. Managerial Auditing Journal, 20(6), 578-591.

Krejcie, R. V. \& Morgan, D. W. (1970). Determining Sample Size for Research Activities. Educational and Psychological Measurement, 30, 607-610.

Ku Ismail, K. N. I. \& Chandler, R. (2005). Perceptions of Professional Investors in Malaysia on the Usefulness of Quarterly Financial Reports. Journal of Management, 24, 105-124.

Kumar, R. (2011). Research Methodology. (3rded.). London: SAGE Publications.

Lymer, A. \& Debreceny, R. (2003). The Auditor and Corporate Reporting on the Internet: Challenges and Institutional Responses. International Journal of Auditing, 7, 103-120.

Marshall, C. \& Rossman, G. B. (1999). Designing Qualitative Research. London. Stage Publication.

Mirshekary, S. \& Saudagaran, S. M. (2005). Perceptions and characteristics of financial statement users in developing countries: Evidence from Iran. Journal of International Accounting, Auditing and Taxation, $14,33-54$.

Mohd Isa, R. (2006). Graphical Information in Corporate Annual Report: A Survey of Users and Preparers Perception. Journal of Financial Reporting and Accounting, 4(1), 39-60.

MohdSanusi, Z., Ismail, A. H., Mat Isa, Y., Tapsir, R., Kasim, S., Muhamad, K., Chantrathevi, T., Zaini, N., Mohd Arif, S. M., Mastuki, N. A. \& Omar, N. (2008). Audit Quality Control: Development of Self- Assessment Checklist for Small and Medium Audit Practices in Malaysia. International Accounting and Business Conference, 18-19 August. Universiti Teknology Mara: Johor, 1-8.

Moradi, M., Salehi, M. and Arianpoor, A. (2011).A Study of the Reasons for shortcomings in establishment of Internet Financial Reporting in Iran. African Journal of Business Management, 5(8), 3312-3321.

Naser, K., Nuseibeh, R. and Al-Hussaini, A. (2003).Users' Perceptions of Various Aspects of Kuwaiti Corporate Reporting. Managerial Auditing Journal, 18(6/7), 599-617.

Ohman, P. and Wallerstedt, E. (2012). Audit Regulation and the Development of the Auditing Profession: The Case of Sweden. Accounting History. 17(2), 241-257.

Ousama, A. A., Fatima, A. H. and Majdi, A. R. H. (2011). Usefulness of Intellectual Capital Information: Preparers' and Users' Views. Journal of Intellectual Capital, 12(3), 430-445.

Oyelere, P., Laswad, F. and Fisher, R. (2003), Determinants of Internet Financial Reporting by New Zealand Companies. Journal of International Financial Management and Accounting.14(1), 1-39.

Radhakrishna, R.B. (2007). Tips for Developing and Testing Questionnaire or Instrument. Journal of Extension. 45(1), 1-4.

Rahman, M.Z. (1998). The Role of Accounting Disclosure in the East Asian Financial Crisis: Lesson Learned. United Nation Conference on Trade and Development. December 1998. Switzerland, 1-38.

Staden, C. J. V. (1998). The Usefulness of the Value- Added Statement in South Africa. Managerial Finance, 24(11), 44-59.

Stoel, D., Havelka, D. \& Merhout, J. W. (2012). An Analysis of Attributes that Impact Information Technology Audit Quality: A Study of IT and Financial Audit Practitioners. International Journal of Accounting Information System, 13, 60-79.

Sumiani, Y., Haslinda, Y. \& Lehman, G. (2007). Environmental Reporting in a Developing Country: A Case on Status and Implementation in Malaysia. Journal of Cleaner Production, 15, 895-901. 
Tan, L. L., Lazar, J. \& Othman, R. (2007). Adoption of Financial Reporting Standards (FRSs): Impact on Malaysian Companies. Malaysian Accountancy Research and Education Foundation, 1-60.

Velmurugan, M. S. (2009). Security and Trust in E-Business: Problem and Prospects. International Journal of Electronic Business Management, 7(3), 151-158.

Virginia, M. C. \& Michael, J. C. (2003).Impact of SAS no.94 on computer audit techniques. Information System Control Journal, 2, 1-9.

Weis, A. H. (2010). Commercialization of the Internet. Internet Research, 20(4), 420-435.

Xiao, J. Z., Jones, M. J. \& Lymer, A. (2002). Immediate Trends in Internet reporting. European Accounting Review, 11(2), 245-276.

Xiao, J. Z., Jones, M. J. \& Lymer, A. (2005).A Conceptual Framework for Investigating the Impact of the Internet on Corporate Reporting. The International Journal of Digital Accounting Research, 5(10), 131-169. 